\title{
Unexpected infiltration of meninges by generalised diffuse large B-cell lymphoma manifesting as multiple cranial neuropathies in a patient with history of breast carcinoma
}

\author{
Eva Malá ${ }^{1}$, Kateřina Matějová ${ }^{1}$, Tomáš Olejár ${ }^{2}$, Radoslav Matěj ${ }^{2,3}$, Adam Pavličko ${ }^{4}$, \\ Ondřej Sobek ${ }^{5}$, Robert Rusina ${ }^{1}$ (B) \\ ${ }^{1}$ Department of Neurology, Third Faculty of Medicine, Charles University and Thomayer University Hospital, Prague, Czech Republic \\ ${ }^{2}$ Department of Pathology and Molecular Medicine, Third Faculty of Medicine, Charles University \\ and Thomayer University Hospital, Prague, Czech Republic \\ ${ }^{3}$ Department of Pathology, First Faculty of Medicine, Charles University, and General University Hospital, Prague, Czech Republic \\ ${ }^{4}$ Department of Radiology, Thomayer University Hospital, Prague, Czech Republic \\ ${ }^{5}$ Laboratory for CSF, Neuroimmunology, Pathology and Special Diagnostics, Topelex, Prague, Czech Republic
}

Key words: meningeal carcinomatosis, subdural haematoma, B-cell lymphoma, cranial neuropathy

(Neurol Neurochir Pol 2021; 55 (5): 499-501)

\section{To the Editors}

Leptomeningeal spread of malignant tumorous cells occurs more commonly in haematological malignancies (incidence of $10-15 \%$ ) and less often with solid tumours such as breast cancer, lung cancer, and melanoma (incidence of 1-5\%) [1]. Diagnostic methods mainly include clinical assessment, cerebrospinal fluid cytological examinations [2], and magnetic resonance imaging (MRI) to distinguish brain metastases from other brain tumours [3]. We present a case of leptomeningeal malignant infiltration in a patient with known breast carcinoma, that initially presented as multiple cranial neuropathies. Surprisingly, but consistent with previous cerebrospinal fluid (CSF) examinations, the autopsy excluded meningeal carcinomatosis by breast cancer malignant cells, and confirmed generalised B-cell lymphoma, including leptomeningeal infiltration.

An 84-year-old female with a history of diabetes, arterial hypertension, and breast cancer diagnosed three years previously and treated by mastectomy and tamoxifen, presented with multiple cranial nerve palsies. Two months before, she had been hospitalised for acute bleeding into a chronic subdural haematoma, which was treated conservatively (Fig. 1A). Clinical examination revealed an incomplete right oculomotor nerve palsy, peripheral left facial nerve palsy, and left leg instability. Laboratory analysis showed only hyperglycaemia. MRI showed haematoma regression and contrast enhancement of the leptomeninges around the right hemisphere (Fig. 1B).

CSF analysis found elevated cell counts and high total protein levels and increased lactate and glucose levels. Empirical antimicrobial therapy with ceftriaxone was initiated, but discontinued soon after due to CSF cultivation; both it and borreliosis serology were negative. Cytomorphological CSF analysis identified atypical cells and another lumbar puncture was performed for a detailed cytological investigation: the cell count was 240 elements per microlitre with enlarged basophilic cells displaying cytoplasmic and nuclear abnormalities, frequent mitosis, and local cohesive tendencies.

The patient was clinically deteriorating, progressing toward somnolence, with progressive right upper and left lower limb weakness, and renal failure. Chronic neuroinfection, however, was still considered the most probable differential diagnosis; ceftriaxone with ampicillin was started, and a third lumbar puncture was performed.

Address for correspondence: Robert Rusina, Department of Neurology, Thomayer University Hospital, Vídeňská 800 Str., 14059 Prague 4 , Czech Republic; e-mail: robert.rusina@lf3.cuni.cz

Received: 24.04.2021 Accepted: 8.05.2021 Early publication date: 2.07.2021

This article is available in open access under Creative Common Attribution-Non-Commercial-No Derivatives 4.0 International (CC BY-NC-ND 4.0) license, allowing to download articles and share them with others as long as they credit the authors and the publisher, but without permission to change them in any way or use them commercially. 


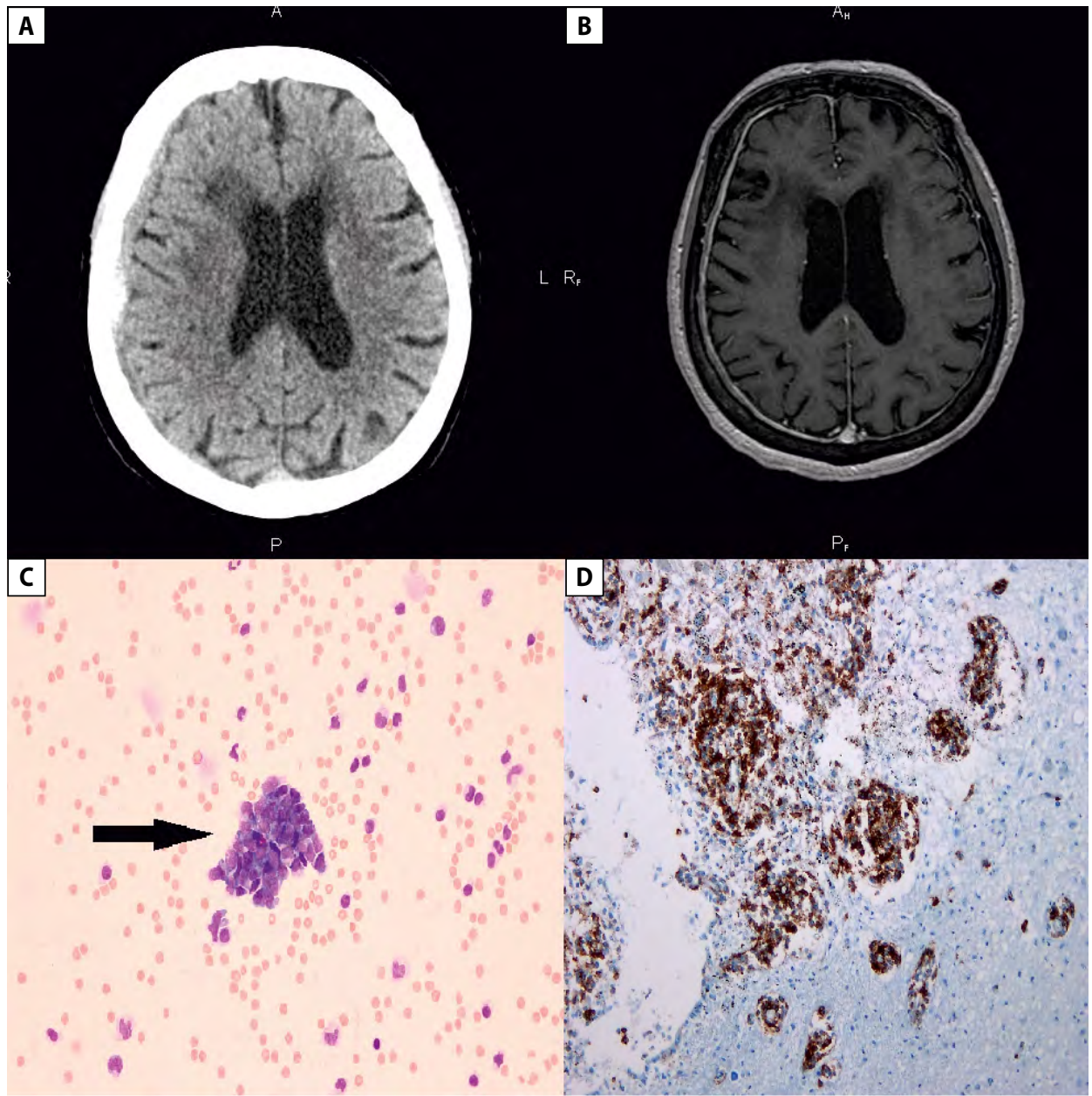

Figure 1. A. Axial non-contrast CT image (two months before disease onset) shows heterogenous subdural effusion above right cerebral convexity, indicating acute bleeding into chronic subdural haematoma; B. Axial T1 contrast-enhanced image shows regression of subdural haematoma with asymmetric enhancement of right-sided dura; C. CSF cytology - a cluster of lymphoma cells (marked by arrow). MayGrunwald Giemsa stain, 40x; D. Neuropathology - diffuse infiltration of meninges at base of mesencephalon by CD20 positive malignant B-cell lymphoma cells. Immunohistochemical staining using an anti-CD20 antibody, 40x

PCRinvestigation excluded the mostlikely pathogens. Immunocytochemical typing of cytologically suspected cells (Fig. 1C) surprisingly identified CD45 and PAX5, both hallmarks of B-cell lymphoma.

The patient's condition continued to deteriorate, and she died 11 days after admission. Autopsy confirmed a massive pulmonary embolism as the cause of death. The major finding concerning the aetiology of meningeal involvement (including the spread to cranial nerves at brain stem level) (Fig. 1D) was a generalised tumour affecting several organs (the lungs, stomach, and lymphatic nodes). A detailed histopathological investigation definitively excluded breast cancer extension, and finally confirmed generalisation of high-grade diffuse large B-cell lymphoma as the source of the leptomeninges infiltration.

Establishing the final diagnosis was a difficult task given the concurrence of the unrelated subdural haematoma and a past history of breast cancer. MRI leptomeningeal enhancement was ascribed initially to the subdural haematoma rather than meningeal infiltration. Moreover, the immunocytochemical investigations of potentially malignant cells in CSF were primarily focused on breast carcinoma.

There have been several published cases with a history of malignancy presenting as a spontaneous nontraumatic subdural haematoma that ultimately turned out to be leptomeningeal tumour infiltration [4-7]. However, in our case the regression of the haematoma (Fig. 1B) confirmed the coincidence of a subdural haematoma and tumour, and not subdural haematoma mimicking [8].

This case report offers guidance regarding patients with a known medical history of malignancy. It is always necessary to consider tumour duplicity and be open to a disorder caused by an entirely new type of tumour (in this case, breast cancer and B-cell lymphoma) [9]. This case clearly demonstrates the 
importance of close cooperation between clinicians, radiologists, and laboratory specialists in establishing the proper diagnosis.

Acknowledgments: The authors wish to thank Tom Secrest for revisions to the English version of this article.

Funding: This work was supported by the Ministry of Health, Czech Republic (Conceptual Development of Research Organisation VFN64165, General University Hospital in Prague and Thomayer University Hospital in Prague, TN64190), by the Grant Agency of the Ministry of Health (NV19-04-00090), and by Charles University (Project Progress Q27/LF1 and Q35/LF3). Conflict of interest: None.

\section{References}

1. Carroll RD, Leigh EC, Curtis Z, et al. A case of leptomeningeal carcinomatosis from aggressive metastatic prostate cancer. Case Rep Oncol. 2019; 12(1): 311-316, doi: 10.1159/000499761, indexed in Pubmed: 31123457.

2. Ma C, Lv Y, Jiang R, et al. Novel method for the detection and quantification of malignant cells in the CSF of patients with leptomeningeal metastasis of lung cancer. Oncol Lett. 2016; 11(1): 619-623, doi: 10.3892/ol.2015.3971, indexed in Pubmed: 26870256.

3. Aslan K, Gunbey HP, Tomak L, et al. Multiparametric MRI in differentiating solitary brain metastasis from high-grade glioma: diag- nostic value of the combined use of diffusion-weighted imaging, dynamic susceptibility contrast imaging, and magnetic resonance spectroscopy parameters. Neurol Neurochir Pol. 2019; 53(3): 227-237, doi: 10.5603/PJNNS.a2019.0024, indexed in Pubmed: 31180131.

4. Boukas A, Sunderland GJ, Ross N. Prostate dural metastasis presenting as chronic subdural hematoma. A case report and review of the literature. Surg Neurol Int. 2015; 6: 30, doi: 10.4103/21527806.151713, indexed in Pubmed: 25737800.

5. Reyes MG, Homsi MF, Mangkornkanong M, et al. Malignant lymphoma presenting as a chronic subdural hematoma. Surg Neurol. 1990; 33(1): 35-36, doi: 10.1016/0090-3019(90)90222-b, indexed in Pubmed: 2300875.

6. Ramnarayan R, Anilkumar TV, Nayar R. An unusual extra-axial hypodense lesion mimicking a chronic subdural haematoma. J Neurosci Rural Pract. 2013; 4(2): 216-219, doi: 10.4103/0976-3147.112774, indexed in Pubmed: 23914111.

7. Neeley OJ, Al-Hreish KM, Aoun SG, et al. Tumoral mimics of subdural hematomas: case report and review of diagnostic and management strategies in primary B-cell lymphoma of the subdural space. World Neurosurg. 2020; 133: 49-54, doi: 10.1016/j.wneu.2019.09.091, indexed in Pubmed: 31562973.

8. Catana D, Koziarz A, Cenic A, et al. Subdural hematoma mimickers: a systematic review. World Neurosurg. 2016; 93: 73-80, doi: 10.1016/j.wneu.2016.05.084, indexed in Pubmed: 27268313.

9. Dušková J, Sobek 0. Assisting the neurologist in diagnosis of CNS malignancies - current possibilities and limits of cerebrospinal fluid cytology and immunocytochemistry. Brain Behav. 2017; 7(10): e00805, doi: 10.1002/brb3.805, indexed in Pubmed: 29075565. 